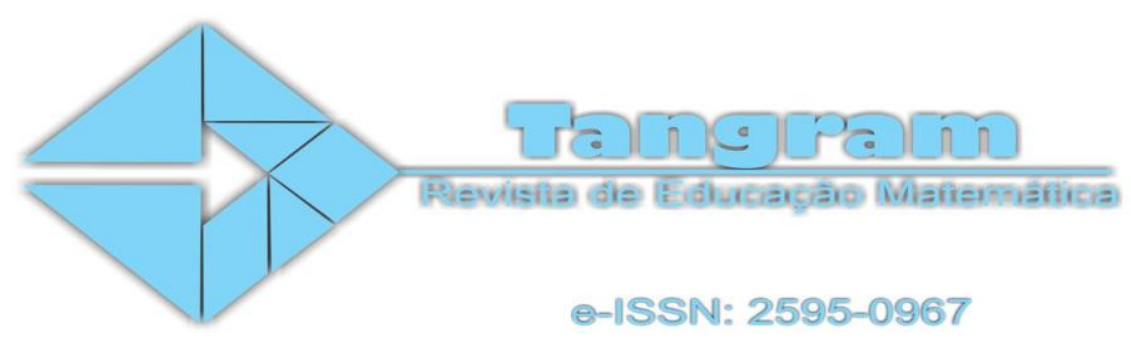

\title{
Algumas técnicas de resolução das equações diofantinas do primeiro grau a duas incógnitas em $\mathrm{Z}$
}

\author{
Some techniques for solving the diophantine equations from the first \\ degree to two unknowns in $Z$
}

\section{Algunas técnicas para resolver ecuaciones de diofantina desde primer grado hasta dos incógnitas en $\mathrm{Z}$}

\author{
Cheick Oumar Doumbia \\ Universidade Estadual de Feira de Santana,Departamento de Matemática \\ Feira de Santana. Bahia,Brasil \\ e-mail:cheickodou@gmail.com \\ Orcid: 0000-0001-8332-4622 \\ Geciara da Silva Carvalho \\ Universidade Estadual de Feira de Santana,Departamento de Matemática \\ Feira de Santana, Bahia,Brasil \\ e-mail: geciara@uefs.br \\ Orcid : 0000-0002-0474-5558 \\ Saddo Ag Almouloud \\ Universidade Federal do Para - Departamento de Matemática \\ Belém, Pará, Brasil \\ e-mail: saddoag@gmail.com \\ Orcid: 0000-0002-8391-7054
}

Enviado:08/05/2020

Aceito:22/06/2020

DOI: $10.30612 /$ tangram.v3i2.11882

Resumo: Este trabalho tem por objetivo evidenciar técnicas de resolução de equações diofantinas visando valorizar os axiomas, teoremas e propriedades desenvolvidos ao longo do curso de licenciatura em matemática, tais como, axioma da escolha, teorema de Euclides, teorema de Bézout, teorema de Gauss, congruências etc. Consideramos nessa pesquisa que existem técnicas eficazes de resolução dessas equações que não emergem nas praxeologias pessoais dos estudantes. Dentro de

Tangram - Revista de Educação Matemática, Dourados - MS - v.3 n.2, pp. 102-126 (2020) 


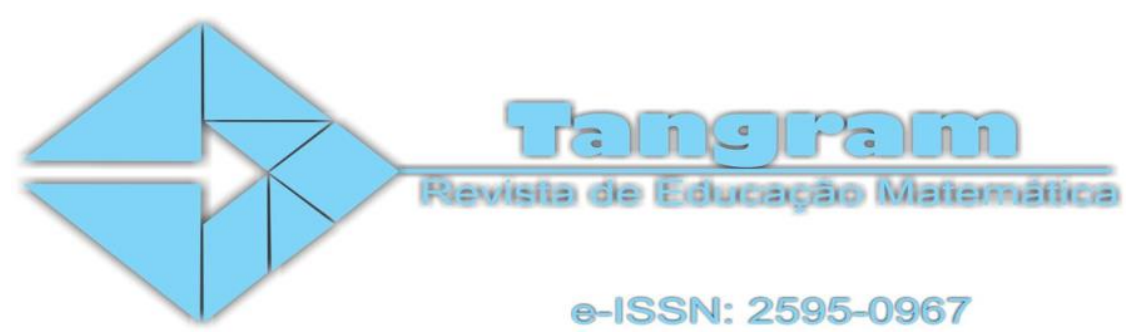

uma perspectiva qualitativa, fizemos uma análise institucional sob o olhar da Teoria Antropológica do Didático. A experimentação evidenciou que existem técnicas que os alunos têm conhecimentos necessários para aplicá-las. Mas, devido às práticas de classe, eles privilegiam as técnicas tentativa e erro, Algoritmo de Euclides / Teorema de Bézout/ Teorema de Gauss, embora elas não se mostrassem sempre eficazes para obtenção das soluções de equações diofantinas lineares de $1^{\circ}$ grau em Z. Portanto, faz-se necessário uma reorganização e rearticulação dos conhecimentos dos estudantes para que possam ampliar suas organizações matemáticas de modo que elas se tornem eficazes na resolução de problemas que envolvem as equações diofantinas.

Palavras-chave: Equações Diofantinas. Organizações Matemáticas. Formação de professores.

Abstract: This work aims to show techniques for solving Diophantine equations aiming at valuing the axioms, theorems and properties developed during the degree course in mathematics, such as, axiom of choice, Euclid's theorem, Bézout theorem, Gauss theorem, congruences etc. In this research, we consider that there are effective techniques for solving these equations that do not emerge in students' personal praxeologies. Within a qualitative perspective, we carried out an institutional analysis under the perspective of the Anthropological Theory of Didactics. Experimentation showed that there are techniques that students have the necessary knowledge to apply them. However, due to class practices, they favor the trial and error techniques, Euclid's Algorithm / Bézout's Theorem / Gauss's Theorem, although they were not always effective in obtaining solutions of first-degree Zlinear Diophantine equations. , it is necessary to reorganize and re-articulate students' knowledge so that they can expand their mathematical organizations so that they become effective in solving problems involving Diophantine equations.

Keywords: Diophantine Equations. Mathematical Organizations. Teacher training.

Resumen: Este trabajo tiene como objetivo mostrar técnicas para resolver ecuaciones diofantinas con el objetivo de valorar los axiomas, teoremas y propiedades desarrollados durante la carrera de grado en matemáticas, tales como, axioma de elección, teorema de Euclides, teorema de Bézout, teorema de Gauss, congruencias, etc. En esta investigación, consideramos que existen técnicas efectivas para resolver estas ecuaciones que no surgen en las praxeologías personales de los estudiantes. Desde una perspectiva cualitativa, realizamos un análisis institucional bajo la perspectiva de la Teoría Antropológica de la Didáctica. La experimentación mostró que existen técnicas en las que los estudiantes tienen los conocimientos necesarios para aplicarlas. Sin embargo, debido a las prácticas de clase, favorecen las técnicas de prueba y error, el Algoritmo de Euclides / Teorema de Bézout / Teorema de Gauss, aunque no siempre fueron efectivas para obtener soluciones de ecuaciones lineales de diofantina $\mathrm{Z}$ de primer grado., es necesario reorganizar y volver a articular el conocimiento de los estudiantes para que puedan expandir sus organizaciones matemáticas para que sean efectivos en la resolución de problemas que involucran ecuaciones de diofantina.

Palabras clave: ecuaciones diofantinas. Organizaciones Matemáticas. Formación de profesores.

Tangram - Revista de Educação Matemática, Dourados - MS - v.3 n.2, pp. 102-126 (2020) 


\section{Introdução}

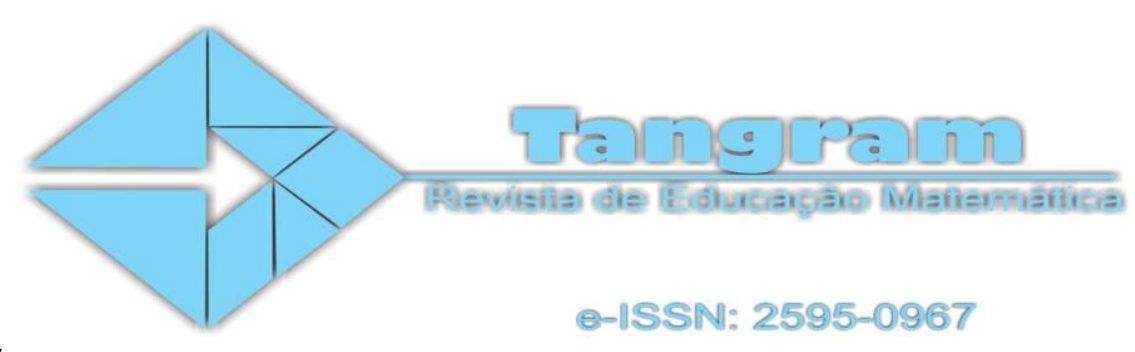

A Teoria dos Números é um dos ramos mais importante da Matemática e o domínio de suas aplicações estão em diferentes ramos da Ciência, como por exemplo, na computação, segurança por meio da criptografia. Este artigo consiste em ampliar as organizações matemáticas das equações diofantinas de um grupo de licenciandos em Matemática visando o desenvolvimento de sua capacidade de compreender, criticar e utilizar novas ideias para a resolução de situação-problema.

Os diversos temas da Teoria dos Números (TN) naturalmente apresentam uma articulação e complementaridade com a Álgebra, possibilitando explorar a escrita da forma algébrica das condições dadas no enunciado, a resolução de equações e sistemas de equações indeterminadas de $1^{\circ}$ grau, além de sua associação à função de $1^{\circ}$ grau. Esta abordagem possibilita que se formulem questões cuja solução completa requer manejo de conceitos de forma integrada, segundo Parâmetro Curriculares Nacionais (1999).

Autores como Groenwald et al. (2005) afirmam que os professores de Matemática da Escola Básica têm dificuldades em propor atividades didáticas adequadas envolvendo os conceitos aritméticos focados na pesquisa, devido à própria característica destes temas em sua não-redutibilidade a fórmulas e algoritmos, bem como a existência de poucas atividades didáticas aplicáveis nos livros de Educação Básica.

A matriz de referência divulgada pelo ENEM, Brasil (2009), propõe que os alunos devam fazer uso das várias linguagens matemáticas, enfrentar situações-problema, por intermédio da seleção, organização e interpretação de informações, representando-as de diferentes formas e tomando decisões, em situações concretas, de modo a construir argumentação consistente.

Autores como Coelho, Machado e Maranhão (2003) consideram a TN um campo apropriado para propiciar o desenvolvimento da chamada "rede de significados", entretanto as autoras também consideram que embora presente nos currículos de alguns cursos de

Tangram - Revista de Educação Matemática, Dourados - MS - v.3 n.2, pp. 102-126 (2020)

Este obra está licenciada com uma Licença Creative Commons Atribuição-NãoComercial-CompartilhaIgual 3.0 Brasil. 


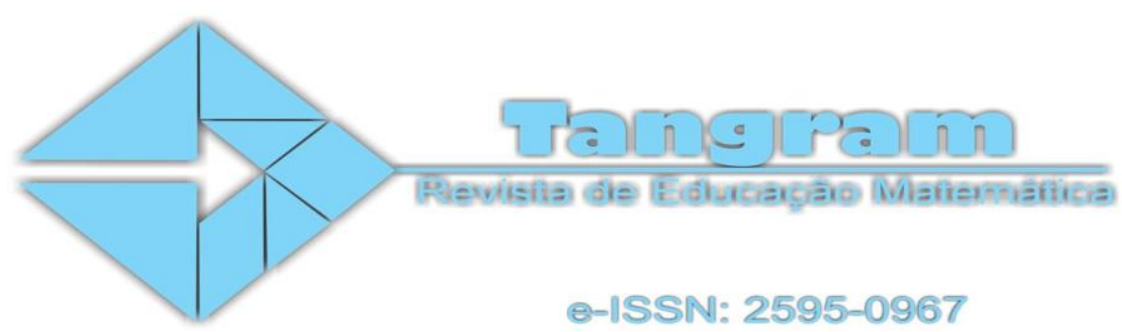

Licenciatura, esta área nem sempre tem sido explorada dessa forma, e pouca atenção tem sido dada a exploração de suas potencialidades como tópico da Educação Básica.

Assim, a abordagem de problemas indeterminados do tipo linear envolvendo equações diofantinas (ED) permite mobilizar uma diversidade de estratégias de resolução em concordância com Pommer e Pommer C. (2012). Além disso, propicia ao estudante compreender o papel da escrita algébrica como agente otimizador, além de criar condições para superar o desafio da articulação aritmética e álgebra visando facilitar a passagem de uma para outra.

Neste contexto, é de suma importância proporcionar aos futuros professores um espaço para discussão e reflexão durante seu processo formativo, sobre a hipótese de estudar e de desenvolver atividades relativas à TN para que esta área da Matemática ganhe mais espaço nos currículos escolares de todos os níveis.

As ED são introduzidas nos cursos de Teoria dos Números e/ou Fundamentos de Álgebra, na licenciatura de Matemática. Sob o olhar das ementas ou plano de ensino de alguns cursos consultados, parece que os professores que lecionam estas disciplinas apresentam somente uma das técnicas de resolução dessas equações, que é uso do Algoritmo de Euclides combinado com os teoremas de Bézout e Gauss. No entanto, existem outras organizações Matemáticas (OM) que envolvem técnicas que se mostram mais eficazes na resolução dessas equações considerando as variáveis didáticas dadas.

Diante do exposto, este trabalho tem por objetivo evidenciar outras técnicas de resolução das ED visando valorizar os axiomas, teoremas e propriedades desenvolvidos ao longo do curso de licenciatura em matemática, tais como, axioma da escolha, teorema de Euclides, teorema de Bézout, teorema de Gauss, congruências etc. Desse modo, o desenho metodológico desta pesquisa é qualitativo, sendo feito uma análise institucional na Educação Básica e no Ensino Superior, acompanhada de aplicação de questionário e entrevistas com estudantes do curso de Licenciatura em matemática da Universidade Estadual de Feira de Santana (UEFS) e análise de livros e planos de ensino, pautada na Teoria Antropológica do Didático de Chevallard (1999).

Tangram - Revista de Educação Matemática, Dourados - MS - v.3 n.2, pp. 102-126 (2020)

Este obra está licenciada com uma Licença Creative Commons Atribuição-NãoComercial-CompartilhaIgual 3.0 Brasil. 


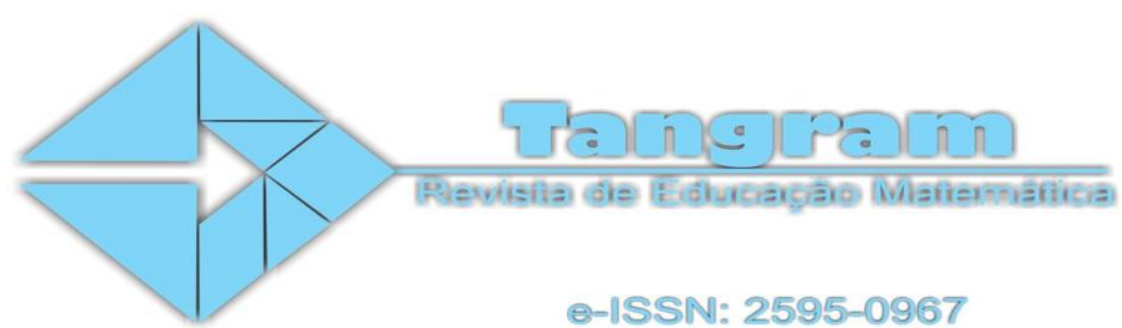

A fase experimental foi destinada para estudantes licenciandos do curso de licenciatura em matemática, futuros professores da Educação básica, visando verificar se nos seus processos formativos estão sendo contemplados o desenvolvimento de habilidades conceituais e pedagógicas dos saberes algébricos necessários para sua atuação em sala de aula voltada para o ensino de técnica para cumprimento de tarefas que envolvem equações diofantinas. Embora sujeitados as noções relativas aos fundamentos da Álgebra e Teoria dos Números na formação dos futuros professores, esses conteúdos aparecem implicitamente na educação básica ao se ensinar, por exemplo, a resolução de equações do tipo ax+ by = c, quando se deseja determinar se tem solução, como resolver e quais técnicas aplicar.

\section{Fundamentos teóricos}

A Teoria Antropológica do Didático (TAD) foi iniciada pelo investigador francês Yves Chevallard pautando-se na concepção do homem fazendo matemáticas no âmbito das instituições sociais. Assim, esta teoria se ocupa da investigação das condições que permitem, facilitam ou favorecem a construção e desdobramentos de determinadas atividades didáticomatemáticas numa dada instituição, bem como das restrições que dificultam, entorpeçam ou, mesmo bloqueiem essas atividades.

A TAD considera que qualquer atividade humana pode ser descrita por um quádruplo $[\mathrm{T}, \tau, \theta, \Theta]$, chamado praxeologia. Essas praxeologias incluem um bloco de práxis (o tipo de tarefa e um conjunto de técnicas) e um bloco do logos que inclui dois níveis de descrição e justificação da práxis (tecnologia e teoria). Dessa forma, uma OM é uma entidade composta por: tipo de tarefas; técnicas, tecnologias e teorias.

Chaachoua \& Bessot (2019) introduzem o constructo 'Praxeologia pessoal". Chamam de Praxeologia pessoal o quádruplo de organização praxeológica aprendida, constituído de quatro componentes: Um tipo de tarefa pessoal, uma técnica pessoal, tecnologia pessoal e uma teoria pessoal. Para os autores,

Tangram - Revista de Educação Matemática, Dourados - MS - v.3 n.2, pp. 102-126 (2020)

Este obra está licenciada com uma Licença Creative Commons Atribuição-NãoComercial-CompartilhaIgual 3.0 Brasil. 


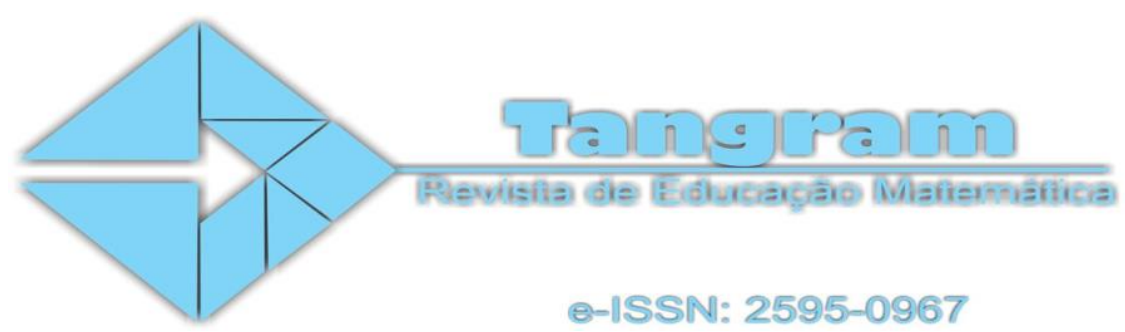

-Um tipo de tarefa pessoal é o conjunto de tarefas que o sujeito percebe como semelhantes, um observável dessa semelhança é a técnica utilizada para realizá-lo. Dois tipos de tarefas pessoais são distintos, se suas respectivas técnicas pessoais forem distintas. A divisão em tipos de tarefas pessoais não corresponde necessariamente a da instituição, caracterizamos esta divisão por valores da variável que podem ser não relevantes do ponto de vista institucional.

- Uma técnica pessoal permite resolver um único tipo de tarefas pessoais: pode ser correta - esperada ou não na instituição, ou errada. Deve ter alguma estabilidade para realizar um tipo de tarefa pessoal no tempo. Assim, evitamos considerar uma técnica pessoal como erros erráticos.

- Fazemos a hipótese que existe uma tecnologia pessoal que pode ser explícita ou não. É importante do ponto de vista da investigação explicar a origem das tecnologias pessoais não só nas condições e restrições institucionais, mas também no processo de estudo vivenciado pelos alunos. Salientamos que uma tecnologia, que ela seja pessoal ou institucional, não é reduzida a um conjunto de teoremas ou regras matemáticas. É um discurso que permite justificar, produzir, tornar inteligível, controlar e adaptar uma técnica. Ela é constituída de vários ingredientes que podem ser da matemática, teoremas em ato, definição em ato, regras do contrato didático ou institucional....

-Uma teoria pessoal que, por sua vez, como o modelo praxeológico institucional, justifica a tecnologia pessoal. (Chaachoua \& Bessot 2019, p. 242, tradução nossa)

Neste artigo pretende-se analisar as OM relativas ao objeto ED instalado no currículo do curso de Licenciatura de Matemática, no âmbito da UEFS. A problemática ecológica consiste em questionar sobre "O que existe e por quê? O que não existe, e por quê? O que poderia existir? Sobre quais condições? Quais objetos são obrigados a viver, ou ao contrário, impedidos de viver, sobre tal conjunto de condições?” (Chevallard, 1997, p. 100). Na perspectiva da TAD também se faz necessário questionar as condições de vida dos objetos de saber nas instituições.

Nesse entendimento, busca-se responder às seguintes questões: o objeto de saber faz parte das recomendações curriculares para o curso de licenciatura? Quais técnicas de resolução das ED emergem nas praxeologias pessoais dos estudantes ao longo das disciplinas do curso? Em quais livros didáticos essas técnicas estão sendo trabalhados? Como é apresentado e com qual finalidade? Esse objeto de saber é efetivamente trabalhado

Tangram - Revista de Educação Matemática, Dourados - MS - v.3 n.2, pp. 102-126 (2020) 


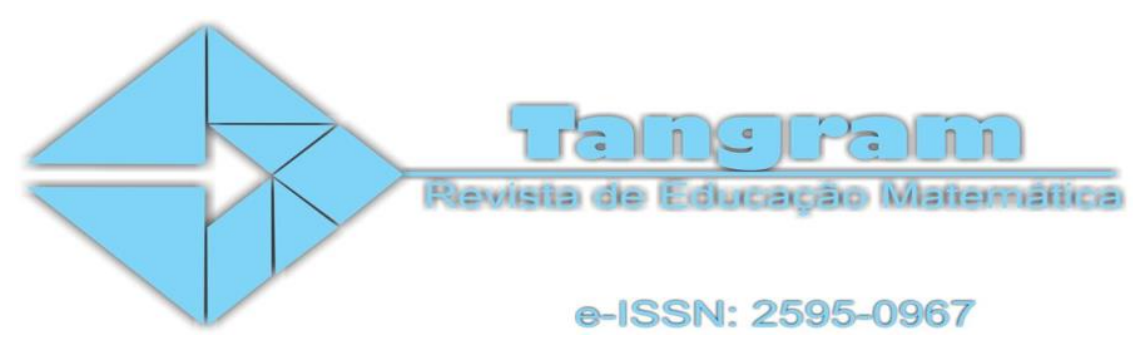

na universidade? Se sim, em quais condições? Se não, quais são os motivos para ser deixado de lado? Como é a sua abordagem ao longo da Educação básica? De acordo com a TAD, a atividade de estudo não é isolada do mundo das atividades sociais nem da dinâmica das instituições.

Um objeto $\mathrm{O}$ existe para uma pessoa $\mathrm{X}$ se existe uma relação pessoal $\mathrm{R}(\mathrm{X}$, $\mathrm{O}$ ), da pessoa X com o objeto O. Do mesmo modo, o objeto O existe para a instituição I se existe uma relação institucional, RI $(\mathrm{O})$, de I com $\mathrm{O}$. Duplamente, diremos que $\mathrm{X}$ (ou I) conhece $\mathrm{O}$ se existe uma relação $\mathrm{R}(\mathrm{X}$, $\mathrm{O})$ de $\mathrm{X}$ com $\mathrm{O}$ (respectivamente, uma relação do RI (O) de I com $\mathrm{O}$ ). (Chevallard, 1991, p. 161)

Nesse sentido, cada saber matemático é resultado de um problema de um grupo social dado e por isso fazer uma análise institucional ajuda a responder essas questões e perceber as relações existentes entre o sujeito (estudante, professor), objeto (conteúdo matemático) e instituição (no caso, ensino básico e superior).

\section{Análise institucional}

Na Base Nacional Comum Curricular (2017), por meio da articulação de seus diversos campos (Aritmética, Álgebra, Geometria, Estatística e Probabilidade), espera-se que os alunos relacionem observações empíricas do mundo real a representações e associem essas representações a uma atividade matemática, conceitos e propriedades, fazendo induções e conjecturas.

$\mathrm{Na}$ visão dos autores, numa perspectiva sociointeracionista, promover em sala de aula atividades que utilizem ED pode criar um ambiente de aprendizagem intrinsecamente relacionado à compreensão, ou seja, à apreensão de significados matemáticos, sem deixar de lado suas aplicações, a partir das interações entre pares. Os significados conceituais obtidos "resultam das conexões que os alunos estabelecem entre eles e os demais componentes, entre eles e seu cotidiano e entre os diferentes temas matemáticos” (Brasil, 2017, p. 232).

Tangram - Revista de Educação Matemática, Dourados - MS - v.3 n.2, pp. 102-126 (2020) 


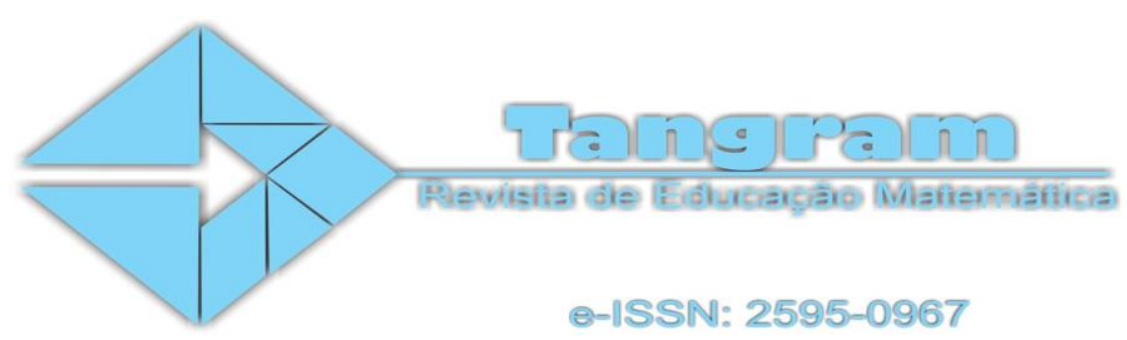

Uma equação diofantina é uma equação algébrica com uma ou mais incógnitas e coeficientes inteiros, para a qual são buscadas soluções inteiras. Uma equação deste tipo pode apresentar distintas soluções, a saber: sem solução, solução única ou infinitas soluções.

Para a equação $a x+b y=c$, em que $a, b \in Z \backslash\{0\}$ e $c \in Z$, temos uma condição necessária e suficiente para a existência de soluções, bem como a forma dessas soluções.

Sejam $a, b \in Z \backslash\{0\}$ e $c \in Z$. Designamos por $\mathrm{d}=$ MDC $(\mathrm{a}, \mathrm{b})$. Mostra-se na teoria dos números que

- $\quad$ Se d não divide c, então a equação $a x+b y=c$ não tem solução em $\mathrm{Z}$.

- Se não, o conjunto das soluções é dado por $\left\{\left(x_{0}+\frac{b k}{d}, y_{0}-\frac{a k}{d}\right), k \in\right.$ $Z\}$ onde $\left(x_{0}, y_{0}\right)$ é uma solução particular.

De fato, se $(x, y)$ é uma solução, então d divide $a x+b y=c$. Portanto, a equação $a x+b y=$ $c$ não tem solução no conjunto $\mathrm{Z}$.

Se d divide $\mathrm{c}$ e que $a x_{0}+b y_{0}=c$ é uma solução particular, temos, então $a\left(x-x_{0}\right)=$ $-b\left(y-y_{0}\right)$. Se designamos por $a^{\prime}=\frac{a}{d} e b^{\prime}=\frac{b}{d}$, temos $a^{\prime}\left(x-x_{0}\right)=-b^{\prime}\left(y-y_{0}\right), \mathrm{a}^{\prime} \mathrm{e}$ b' sendo número primos entre se. Assim, de acordo com o lema de Gauss, á divide $y$ - $y_{0}$, ou seja, existe $k \in \mathrm{Z}$ tal que $y=y_{0}-a^{\prime} k$. Substituindo esse valor na equação, temos $x=x_{0}+\mathrm{b}^{\prime} k$. Neste trabalho serão consideradas situações-problema envolvendo implicitamente a busca de soluções inteiras das ED da forma $\boldsymbol{a x}+\boldsymbol{b y}=\mathbf{c}, \operatorname{com} \boldsymbol{a}, \boldsymbol{b}, \boldsymbol{c} \in \mathrm{Z}$.

Ainda, a natureza deste objeto possibilita o uso de diversas estratégias de resolução, mais usualmente tentativa e erro, pois perpassa dois aspectos:

o aritmético: a condição necessária e suficiente para que exista solução para esse tipo de equação é que o máximo divisor comum de a e b divida c; o algébrico: a representação algébrica desse tipo de equação permite desenvolver o pensamento algébrico e a representação de uma linguagem generalizante, viabilizado pelo uso da escrita algébrica como condição otimizadora das condições dadas no enunciado. (Pommer, 2005, p. 23)

Tangram - Revista de Educação Matemática, Dourados - MS - v.3 n.2, pp. 102-126 (2020) 


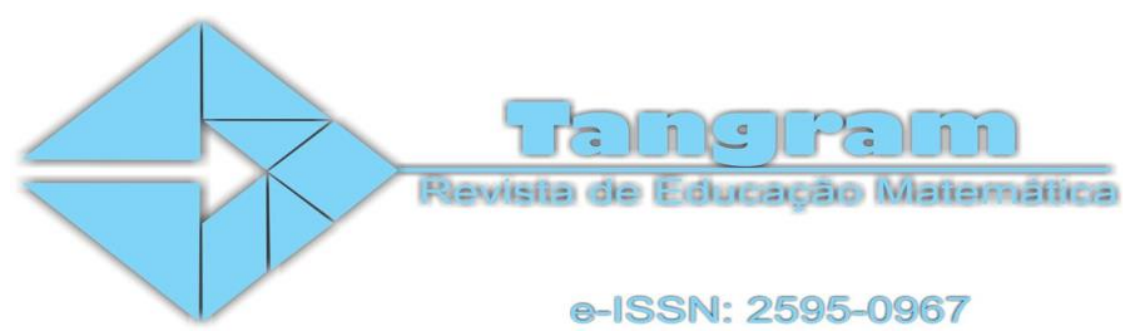

Este modo de "fazer" embora limitado e custoso permite a mobilização de saberes de forma integrada, no ensino básico, estabelecendo uma natural transição entre a aritmética e a álgebra, que quando também intermediado por tecnologias digitais, por exemplo, o Geogebra permite obter os pares do plano cartesiano que satisfaz a reta de equação $\boldsymbol{a x}+$ $\boldsymbol{b} \boldsymbol{y}=\boldsymbol{c}, \operatorname{com} \boldsymbol{a}, \boldsymbol{b}, \boldsymbol{c} \in \mathrm{Z}$, facilitando ao leitor obter o conjunto solução da equação dada. $\mathrm{O}$ aspecto gráfico da ED, embora não citado por Pommer (2005), pode tornar o processo de obtenção da solução simplificado e, portanto, econômico, segundo as dimensões do problema didático estabelecido por Gascón (2011).

As ED aparecem na primeira vez no sétimo ano do ensino fundamental II nos livros didáticos, tal conceito encontra-se implicitamente nos capítulos que tratam de Equações do $1^{\circ}$ grau com duas incógnitas. As competências identificadas para o desenvolvimento do conceito nos livros didáticos consistem em definir equação de $1^{\circ}$ grau com duas incógnitas; identificar equação com duas incógnitas; traduzir e escrever uma situação real mediante equações de $1^{\mathrm{o}}$ grau com duas incógnitas; Verificar se um par ordenado, cujos elementos pertencem aos números inteiros é solução da equação dada, bem como mostrar que a ordenação a dupla altera a solução da mesma; Resolver graficamente uma equação do $1^{\circ}$ grau, visando mostrar que a reta representa o conjunto de soluções da equação dada.

No $8^{\circ}$ ano, além dessas competências citadas anteriormente, inicia a ampliação da algebrização a partir da definição das equações literais. No $9^{\circ}$ ano, além dessas competências anteriormente citadas, percebe-se uma generalização do conceito mediante o conceito de função afim. De igual modo, as ED aparecem principalmente em situações-problema, mas também reaparecem implicitamente no $2^{\circ}$ ano do ensino médio quando é apresentado o conteúdo de Sistemas lineares. As competências referem-se aos tipos de tarefas nesse habitat $^{1}$. As técnicas que sustentam os tipos de tarefas nesse contexto são: tentativa e erro, e exploração do gráfico de funções.

${ }^{1}$ Instituição ou lugar onde vivem o objeto matemático e os que eles estão associados

Tangram - Revista de Educação Matemática, Dourados - MS - v.3 n.2, pp. 102-126 (2020)

Este obra está licenciada com uma Licença Creative Commons Atribuição-NãoComercial-CompartilhaIgual 3.0 Brasil. 


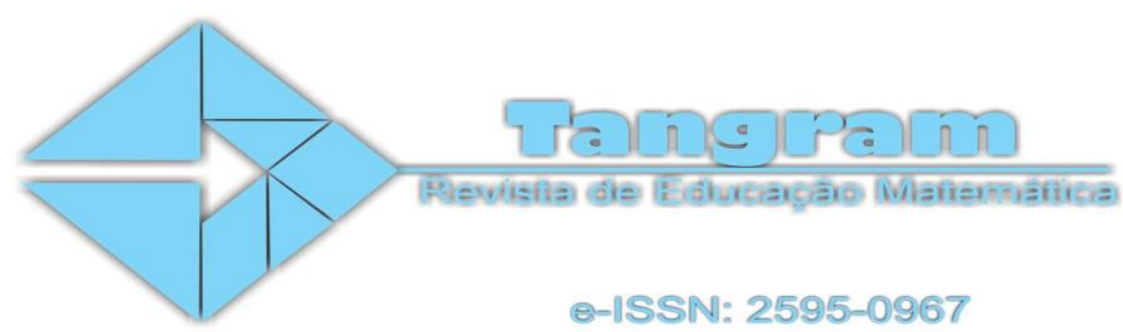

No ensino superior, as ED são apresentadas privilegiando a aplicação das técnicas do algoritmo de Euclides e teorema de Gauss. Esta percepção está baseada na análise de planos de curso e/ou ementa, e nas respostas dos exercícios ilustrativos do curso na UEFS.

Deste estudo percebe-se que o objeto vive em diferentes instituições, tem hábitat e nichos ${ }^{2}$ definidos em virtude de sua presença implícita no currículo do $7^{\circ}$ ao $2^{\mathrm{a}}$ ano do ensino médio e explicita no ensino superior. Percebeu-se que a técnica tentativa e erro ${ }^{3}$ é a esperada no ensino básico, em razão das outras técnicas viverem na Educação Superior. Entretanto, embora essas técnicas sejam esperadas no currículo dos cursos de formação de professores de matemática, em particular do curso de licenciatura em matemática da UEFS, público alvo desta pesquisa, identificou-se a ausência de outras técnicas de resolução de ED, bem como da articulação/aplicação em outros contextos não matemáticos.

Encontra-se ainda que uma das razões de ser das ED na Educação básica consiste em possibilitar a expressão e argumentação do estudante em diferentes linguagens dentro da própria Matemática (natural, numérica, algébrica, gráfica). Para Pommer (2005, p. 24), este conteúdo favorece

[...] diversas situações-problema contextualizadas, que possibilitam ao aluno agir, formular e tomar decisões que extrapolam a capacidade de uma forma original, favorecendo o surgimento de múltiplas possibilidades de encaminhamentos e exploração de diversos pontos de vista.

Em função disto, foi construída uma situação experimental com a finalidade de fazer um levantamento das organizações matemáticas disponíveis nos estudantes de licenciatura da UEFS, futuros professores da Educação básica.

\footnotetext{
${ }^{2}$ Correspondem às relações/função ocupado pelo objeto matemático no habitat

${ }^{3}$ Consiste na escolha aleatória de valores que satisfazem a equação dada, após a sua verificação
}

Tangram - Revista de Educação Matemática, Dourados - MS - v.3 n.2, pp. 102-126 (2020) 


\section{Parte experimental}

A experimentação ocorreu com estudantes do $3^{\circ}$ semestre do curso de Licenciatura em matemática, que estavam cursando a disciplina Instrumentação para o Ensino de Matemática III que tem como pré-requisito a disciplina Teoria dos Números. Esta disciplina visa estudar conceitos referentes a aritmética e propiciar aos licenciandos vivências que simulam o ensino dos fundamentos da aritmética na Educação Básica. Esta escolha se deu pelo fato de os estudantes terem cursado os fundamentos da teoria dos números e em paralelo a esta disciplina, estarem cursando fundamentos da Álgebra.

A organização social da classe foi arquitetada em grupos de 4 a 5 alunos, para um total de 17 alunos. Cada grupo recebeu a atividade completa com folha de resposta comum, sendo que cada participante recebeu folha para rascunho para favorecer a discussão no seio do grupo que teve um secretário para formalização da resposta comum. Foi feita a observação pelos dois primeiros professores pesquisadores e o professor da turma durante 2 horas de aula mais uma hora de discussão com correção da atividade visando à descrição das técnicas utilizadas pelos alunos que não apareceram nas respostas observadas no momento da experimentação. Durante a atividade foram feitos registros pelos professores observadores para identificar o que estava acontecendo no seio de cada grupo sem influenciar na resolução das questões dadas.

Para construir a experimentação foram escolhidas as seguintes variáveis didáticas ${ }^{4}$ : o grau da equação diofantinas, os coeficientes e o conjunto de referência ou o conjunto no qual se faz a resolução. A atividade consistiu na resolução de uma situação-problema composta de duas partes, como seguem:

\section{PARTE I}

\footnotetext{
${ }^{4}$ Segundo Brousseau (1982a), um campo de problemas pode ser gerado a partir de situação alterando os valores de certas variáveis que, por sua vez, mudam as características das estratégias solução (custo, validade, complexidade ... etc.) [...] Apenas alterações que afetam a hierarquia das estratégias devem ser considerados (variáveis relevantes) e entre as variáveis relevantes, aqueles que podem ser manipulados por um professor são particularmente interessante: estas são as variáveis didáticas.
}

Tangram - Revista de Educação Matemática, Dourados - MS - v.3 n.2, pp. 102-126 (2020) 


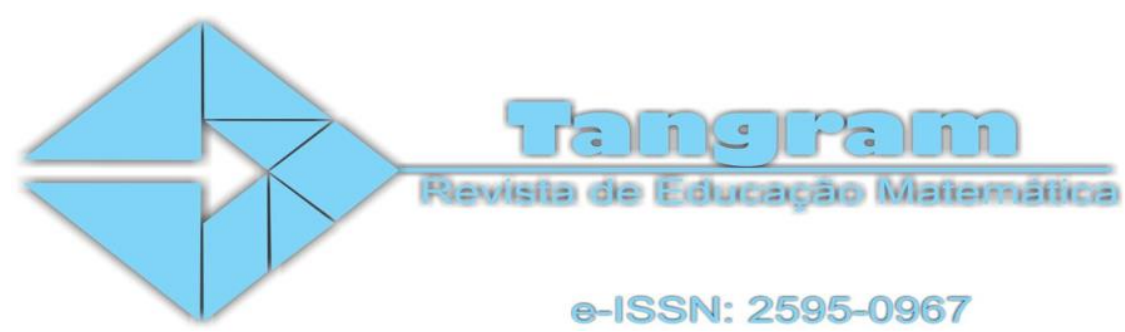

1. Resolva a equação $a x+b y=c$, onde $a, b$ e $c$ são números inteiros, nos seguintes casos, utilizando todas as técnicas conhecidas:
a) $a=2, b=5$ e $c=0$
b) $a=2, b=5$ e $c=3$
c) $a=12, b=35$ e $c=15$
d) $a=15, b=41$ e $c=-30$

Quais são as técnicas/métodos de resolução que podem ser utilizados na resolução das equações acima listadas?

\section{PARTE II}

2. Para incrementar a frota de veículos, uma corporação militar adquiriu automóveis e motocicletas. Considerando que a soma dos pneus de cada moto e dos pneus de cada automóvel é igual a 152 pneus, quantos motos e carros foram adquiridos pela corporação militar?

3. Considere um perímetro de $30 \mathrm{~m}$, quantos retângulos com lados inteiros podem ser formados com essa medida?

4. Ana Clara dispõe de um número $\mathrm{x}$ de fotos para distribuir em um álbum. Ao tentar colocar 10 fotos em cada página, Ana Clara percebeu que sobrariam 8 fotos. Ao tentar colocar 12 fotos em cada página, acabou sobrando mais uma vez 8 fotos. Em uma terceira tentativa, Ana Clara tentou colocar 15 fotos em cada página, e mais uma vez percebeu que sobrariam 8 fotos. Sabendo que x é um número entre 130 e 190, se Fernanda colocar oito fotos em cada página, então...

\section{Análise a priori}

A parte I objetivou saber quais são as técnicas/métodos de resolução que os alunos podem mobilizar para resolver as $\mathrm{ED}$, do tipo $a x+b y=c$, onde $\mathrm{a}$, b e c são números inteiros.

Tangram - Revista de Educação Matemática, Dourados - MS - v.3 n.2, pp. 102-126 (2020) 


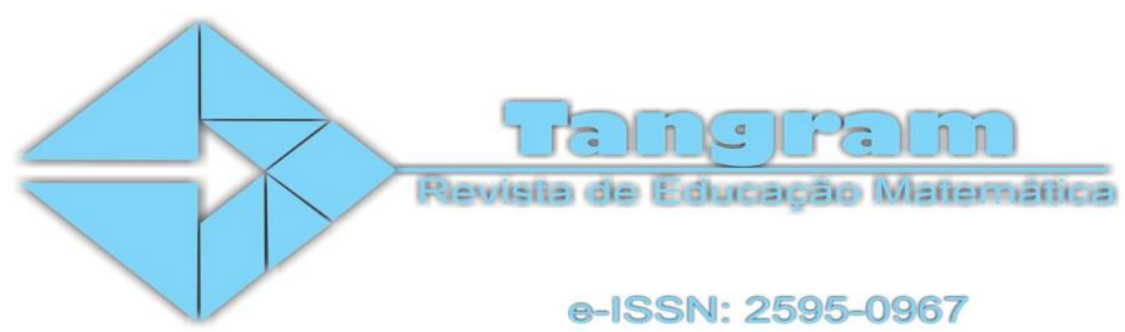

O tipo de tarefa neste caso constitui em resolver a equação diofantina linear de $1^{\circ}$ grau do tipo $a x+b y=c$, onde $a, b$ e $c \in \mathbb{Z}$ e $a \neq 0$ e $b \neq 0$.

As técnicas esperadas para resolução dessas equações são:

$\left[\tau_{1}\right]$ : tentativa e erro, técnica que consiste em dar um valor inteiro a $x$ e buscar o valor de $y$. O complexo tecnológico/teórico é o axioma de Escolha.

$\left[\tau_{2}\right]$ : O olgoritmo de Euclides / Teorema de Bézout/ Teorema de Gauss, consiste em buscar o $\operatorname{MDC}(a, b)$ a partir de uma tabela chamada algoritmo de Euclides e usar o teorema de Bézout para achar uma solução particular da ED dada e usar o teorema de Gauss para achar a solução geral. As tecnologias que as sustentam são os teoremas de Euclides, Bézout e de Gauss.

Descrevemos a seguir o algoritmo de Euclides. Designamos por $\mathrm{D}(\mathrm{x})$ o conjunto dos divisores positivos de um número inteiro de $x \in \mathrm{Z}$ (conjunto dos números inteiros. Descrevemos em três passos o algoritmo de Euclides.

- Passo 1: dados dois inteiros naturais a e b, com b diferente de zero, fazemos a divisão euclidiana de a por b. Temos: $a=b . q_{0}+r_{0} \operatorname{com} 0 \leq r_{0}<b$ e provamos que $\mathrm{D}(a) \cap \mathrm{D}$ $(b)=\mathrm{D}(b) \cap \mathrm{D}\left(r_{0}\right)$.

- Etapa 2: se $r_{0} \neq 0$, repetimos a etapa 1 com o par $\left(b ; r_{0}\right)$, assim, $b=q_{1} \cdot r_{0}+r_{1} \operatorname{com} 0$ $\leq r_{1}<r_{0}$. Temos então $\mathrm{D}(a) \cap \mathrm{D}(b)=\mathrm{D}(b) \cap \mathrm{D}\left(r_{0}\right)=\mathrm{D}\left(r_{0}\right) \cap \mathrm{D}\left(r_{l}\right)$. E assim por diante, construímos uma sequência $\left(r_{n}\right)$ de números inteiros $r_{0}, r_{l}, \ldots, r_{n}$ satisfazendo $0 \leq r_{n}<r_{n-1}<\ldots<r_{1}<r_{0}$ e $\mathrm{D}(a) \cap \mathrm{D}(b)=\mathrm{D}\left(r_{n-1}\right) \cap \mathrm{D}\left(r_{n}\right)$. Esse processo é necessariamente finalizado porque $\left(r_{n}\right)$ é uma sequência estritamente decrescente de números naturais.

- Passo 3: o último passo ocorre quando o primeiro zero permanece, se $r_{n}=0 \mathrm{com} r_{n^{-}}$ $1 \neq 0$, temos $\mathrm{D}(a) \cap \mathrm{D}(b)=\mathrm{D}\left(r_{n-1}\right) \cap \mathrm{D}(0)=\mathrm{D}\left(r_{n-1}\right) . \mathrm{O}$ PGCD de $a$ e $b$ é, portanto, igual ao último restante diferente de zero obtido nas divisões sucessivas.

No processo de resolução de uma equação diofantina, o teorema de Gauss é importante, pois auxilia na procura de MDC de dois números inteiros. O teorema afirma

Tangram - Revista de Educação Matemática, Dourados - MS - v.3 n.2, pp. 102-126 (2020) 


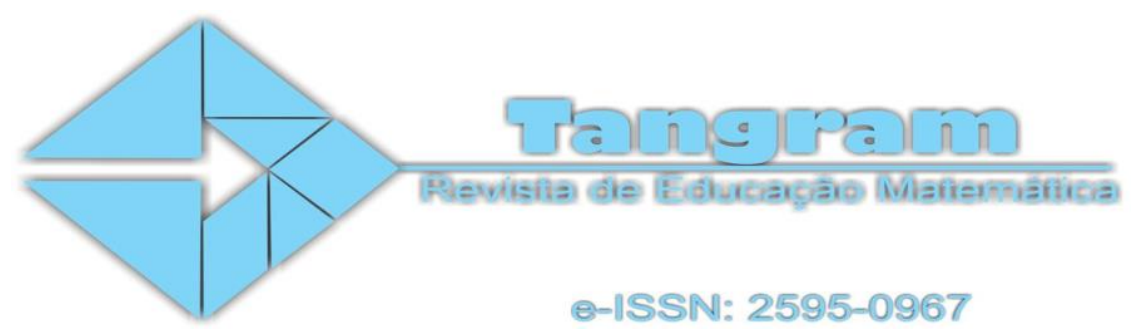

que se $a$ divide o produto $b . c$ e, $a$ e $b$ primos entre si, então $a$ divide $c$. Além disso, de acordo com o teorema de Bézout, se $a$ e $b$ são dois inteiros naturais não nulos, e $d=$ MDC $(a, b)$, então existem dois números inteiros $u$ e $v$ tais que $a \cdot u+b \cdot v=d$. Dois números inteiros naturais $a$ e $b$ são primos entre si, se, e somente, existem dois inteiros $u$ e $v$ tais que $a \cdot u+b \cdot v=1$.

$\left[\tau_{3}\right]$ : Congruência: ela consiste em evidenciar a incógnita de coeficiente maior em função daquela de menor coeficiente e buscar o inverso do maior coeficiente em $\mathrm{Z} / m \mathrm{Z}$ onde $m$ é o menor coeficiente e substituir. A tecnologia que a justifica são as propriedades das operações em Anéis.

$\left[\tau_{4}\right]$ : Teorema de Gauss, técnica mais eficaz quando $c$ for 0 (Se $a / b c$ ( $a$ divide $b c$ ) e $a$ não divide $b$ então $a / c$, com, $a, b, c \in \mathbb{Z}$ ). O complexo tecnológico/teórico é o teorema de Gauss. $\left[\tau_{5}\right]$ : Divisibilidade em $\mathrm{Z}$, esta técnica se aplica quando um dos coeficientes a ou b divide $\mathrm{c}$, ela consiste em escrever a ED na forma $x=p+\frac{b}{a y}$, com $a$ e $b$ primos, então $y=a k$ para que $x$ seja inteiro mediante $x=p+b k, k \in \mathbb{Z}$. O complexo tecnológico/teórico que justifica essa técnica é o teorema de Euclides.

Dentre essas técnicas, buscou-se analisar aquela que é mais econômica segundo definição dada por Gascón (2011), assim considerado, temos:

a) $a=2, b=5$ e $c=0$.

Seja $2 x+5 y=0$, como $2 / 0$ e $5 / 0$ e são primos, então pode-se escrever $2 x=-5 y$. De acordo com o teorema de Gauss $2 / y$ e, portanto, $\exists k \in \mathbb{Z}$ tal que $\mathrm{y}=2 k$. Consequentemente, $x=-5 k, 2 x=-5 y, k \in \mathbb{Z}$. A solução geral é $\{(-5 k, 2 k), k \in \mathbb{Z}\}$.

A técnica $\left[\tau_{1}\right]$ não permite calcular todas as soluções. É possível utilizar a técnica $\left[\tau_{2}\right],\left[\tau_{3}\right]$ : e $\left[\tau_{5}\right]$. No entanto, estas são muito custosas que a aplicação da $\left[\tau_{4}\right]$. Assim esta técnica se constitui mais adequada quanto à dimensão econômica. Sua aplicação se justifica em contexto onde $\mathrm{c}=0, \forall a, b, \in \mathbb{Z}$ tem que $a / 0$ e $b / 0$.

b) $\quad a=2, b=5$ e $c=3$

Tangram - Revista de Educação Matemática, Dourados - MS - v.3 n.2, pp. 102-126 (2020) 


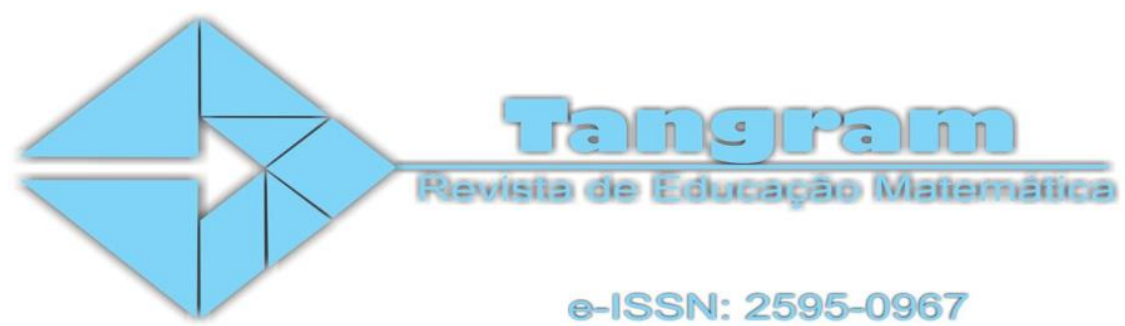

Seja $2 x+5 y=3, o \operatorname{MDC}(2,5)=1$ e sendo 2 e 5 são primos entre si, como $1 / 3$ então existe solução. Por intermédio do Teorema de Bézout que diz que dados a e b dois números inteiros não nulos simultaneamente e seja $d=\operatorname{MDC}(a, b)$; nestas condições, existem inteiros $r$ e $s$ tais que; $d=r \cdot a+s \cdot b$. Sendo $5 y=3-2 x$ então $y=\frac{3-2 x}{5}$. Pela técnica $\left[\tau_{1}\right]$, obtém-se uma solução evidente, como por exemplo, $x=-3$ e $y=9$.

A $\left[\tau_{3}\right]$ é a mais econômica, pois sendo $5 y=3-2 x \Rightarrow 5 y=3 \bmod 2 \Rightarrow 4 y+y=$ $3 \bmod 2$. Como $4 y=0 \bmod 2$ e $3=1 \bmod 2$ então $y=1 \bmod 2$. Assim, $y=1+2 k \mathrm{e}$ substituindo na equação inicial se obtêm $x=1-k, k \in \mathbb{Z}$, compondo a solução geral. Sua aplicação se justifica em contexto onde, a não divide c e d não divide b, sendo a e b menores que 10. Portanto, não se utiliza o teorema de Gauss. A técnica $\left[\tau_{2}\right]$ é penosa em comparação à teoria das congruências.

c) $a=12, b=35$ e $c=15$

Seja $12 x+35 y=15$, o $\operatorname{MDC}(2,5)=1$ e sendo 12 e 35 são primos entre si, como $1 / 15$ então existe solução. Pelo algoritmo de Euclides, tem-se: $35=12 \cdot 2+11 \Leftrightarrow 11=$ $35-12 \cdot 2$ e $12=11 \cdot 1+1 \Leftrightarrow 1=12-11 \cdot 1$. Assim, $1=12-(35-12 \cdot 2) \Rightarrow 1=$ $12 \cdot 3-35 \cdot 1 \times 15 \Rightarrow 15=12 \cdot(45)+35 \cdot(-15)$. Uma solução particular é $S=$ $\{(45,-15)\}$.

A solução geral é obtida por meio do sistema de equações $\left\{\begin{array}{c}12 x+35 y=15 \\ 12 \cdot(45)+35 \cdot(-15)=15\end{array}\right.$ e pela aplicação do teorema de Gauss. Logo,

$$
12(x-45)+35(y+15)=0 \Rightarrow 12(x-45)=35(-y-15) \Rightarrow 12 /(-y-15) \Rightarrow
$$
$\exists k \in \mathbb{Z}$ tal que $-15-y=12 k$. Logo, $y=-15-12 k$.

A solução é $\{(45+35 k,-15-12 k), k \in \mathbb{Z}\}$.

Assim, a $\left[\tau_{4}\right]$ é a mais adequada, e aplica-se nos casos onde, a não divide c e b não divide c e com a, b maiores que 10 .

d)

$$
a=15, b=41 \text { e } c=-30
$$

Tangram - Revista de Educação Matemática, Dourados - MS - v.3 n.2, pp. 102-126 (2020) 


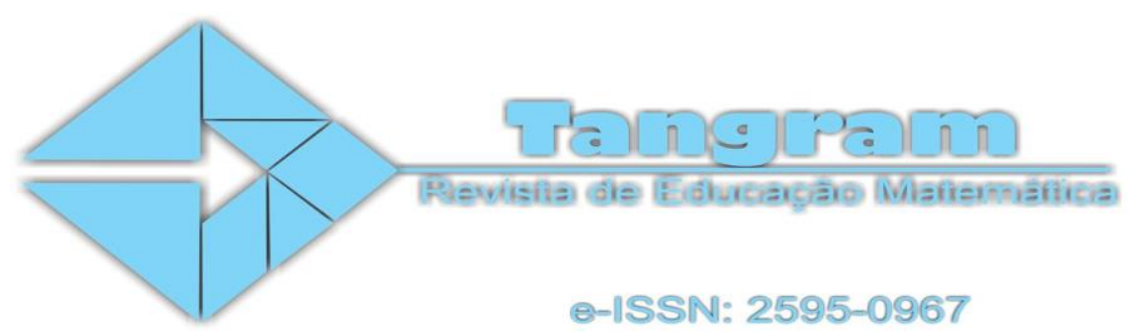

Seja $15 x+41 y=-30$. Fazendo $15 x=-30-41 y$, tem-se $x=\frac{-30-41 y}{15}$ $\Rightarrow x=-2-\frac{41}{15} y$. Para que $x \in \mathbb{Z}$ é necessário que $y=15 k, \mathrm{k} \in \mathbb{Z} . \operatorname{Logo}, x=-2-41 k$. Assim, nenhuma das técnicas usadas anteriormente é a mais adequada, e neste caso, aplicase a propriedade resultante da definição de divisibilidade em $\mathbb{Z}$, a técnica $\left[\tau_{5}\right]$, qual seja, $a$ ou $b$ divide $c$, então evidencia $x$ em função de $y$, obtendo

$$
y=a k \text { e } x=a^{\prime}+b k, k \in \mathbb{Z} .
$$

Diante do exposto, as respostas previsíveis dos estudantes nos casos apresentados são:

- Utilizar a técnica $\left[\tau_{1}\right]$, e achar uma solução particular encontrando dúvidas na busca da solução geral.

- Aplicar a técnica com resolução penosa, ampliando a probabilidade de ocorrência de erros na sua aplicação.

- Algumas técnicas como $\left[\tau_{3}\right]$ a $\left[\tau_{5}\right]$ não serão encontradas nas produções dos estudantes, por causa da ausência de inter-relação dos conhecimentos matemáticos e sua aplicação na própria matemática, nas práticas de classe dos docentes.

- Representar graficamente as equações para identificar graficamente uma solução particular e depois buscar a solução geral. No entanto, a ênfase geométrica pouco é trabalhada nos livros de teoria dos números ou fundamentos de álgebra consultados.

Na parte II foram escolhidos problemas abertos objetivando verificar se em situações do dia a dia os licenciandos são capazes de mobilizar competências adquiridas sobre as ED de $1^{\circ}$ grau em $\mathbb{Z}$ para resolver problemas.

Na questão 2, ao encontrar a solução geral dada que atenda a condição dada $2 x+$ $4 y=152$, obtém-se $x=2 k$ e $2 \mathrm{y}=-2 k+76 \Rightarrow y=38-k$. Ao voltar ao contexto da questão,

Consideram-se as seguintes restrições: $\mathrm{x}>0$ e $\mathrm{y}>0$, consequentemente têm-se:

$$
\left\{\begin{array}{l}
0 \leq x \leq 76 \\
0 \leq y \leq 38
\end{array}\right.
$$

Tangram - Revista de Educação Matemática, Dourados - MS - v.3 n.2, pp. 102-126 (2020) 


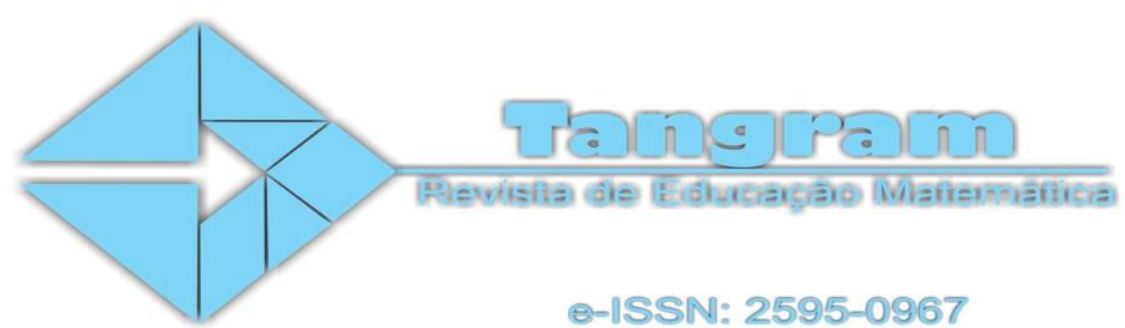

Logo, $0 \leq 2 k \leq 76 \Rightarrow 0 \leq k \leq 38$. Fazendo $k=1,2, \ldots, 38$, obtêm-se $(0,38)$, $(2,37),(4,36),(6,35),(8,34),(10,33),(12,32),(14,31),(16,30),(18,29),(20,28),(22,27)$, $(24,26),(26,25),(28,24),(30,23),(32,22),(34,21),(36,20),(38,19),(40,18),(42,17)$, $(44,16),(46,15),(48,14),(50,13),(52,12),(54,11),(56,10),(58,9),(60,8),(62,7),(64,6)$, $(66,5),(68,4),(70,3),(72,2),(74,1),(76,0)$. Temos 39 soluções.

Na questão 3, deseja encontrar a quantidade de retângulos de perímetro $30 \mathrm{~m}$ que podem ser formados. Para tanto, considera-se $2 x+2 y=30 \Rightarrow x+y=15 \Rightarrow x=15-$ $y$. Fazendo $y=k$, encontra-se $x=15-k$. Sendo os lados do retângulo inteiros, com as seguintes restrições impostas: Como , portanto, $k=1,2, \ldots, 14$.

Entretanto, são 7 retângulos que satisfazem a condição dada, pois o retângulo de $\operatorname{lados}(1,14)$ e $(14,1)$ são os mesmos.

Nessas questões comentadas, a técnica $\left[\tau_{5}\right]$ foi utilizada por ser mais adequada ao contexto dado. Entretanto, outras técnicas seriam possíveis de serem aplicadas nesses casos.

No desenvolvimento dessa questão é imediato que $10 x+8=12 y+8=15 z+8 \Rightarrow$ $10 x=12 y=15 z$. Dessa forma, tem-se $(\mathrm{X}-8)$ é um múltiplo comum de 10, 12 e 15. Consequentemente $\mathrm{X}-8=60 k, k \in \mathbb{N}$.

Por outro lado, temos $130 \leq X \leq 190$. Daí, $130-8 \leq X-8 \leq 190-8 \Rightarrow 122 \leq$ $60 k \leq 182 \Rightarrow 2,0333 \ldots \leq k \leq 3,0333 \ldots \Rightarrow k=3$. Portanto, $\mathrm{X}=188$. Isto resulta em Ana Clara colocar 8 fotos por página então sobrarão 4 fotos.

As dificuldades que os alunos podem enfrentar dizem respeito à modelização dos problemas dados a partir das técnicas de resolução das ED. Outro aspecto que possivelmente embaraça o estudante depois de encontrar a solução geral da ED aplicável no problema seria adequá-la a realidade da situação-problema dada.

Os estudantes poderão utilizar $\left[\tau_{1}\right]$ para achar a solução do problema; mas é penosa e custa muito tempo.

\section{Análise a posteriori}

Tangram - Revista de Educação Matemática, Dourados - MS - v.3 n.2, pp. 102-126 (2020) 


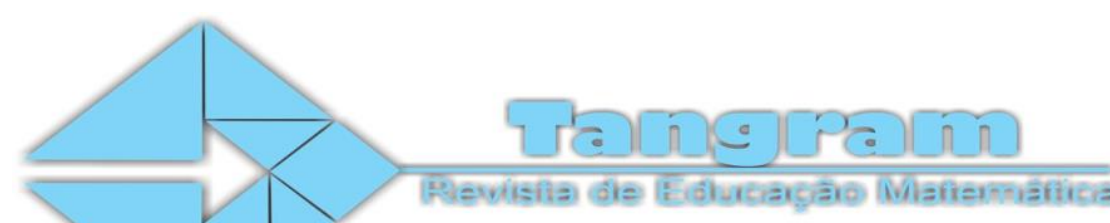

\section{e-1SSN: 2595-0967}

Para analisar os resultados da experimentação foi feita o quadro 1 que tem por objetivo mostrar os tipos de técnicas apresentadas na folha de resposta de cada grupo, além de explicitar a modelização dos problemas dados com a apresentação correta ou não de suas soluções.

A partir da análise da produção dos grupos percebe-se que a técnica $\left[\tau_{3}\right]$ não apareceu nos registros da parte I da atividade. Entretanto, conforme imagem I da figura 1, observa- se uma tentativa de utilização da teoria das congruências sem sucesso na questão 4 do grupo 4, mesmo encontrando a solução correta pela técnica tentativa e erro.

Quadro 1- técnica apresentadas pelos alunos

\begin{tabular}{|c|c|c|c|c|c|c|}
\hline 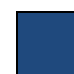 & PARTE I & {$\left[\tau_{1}\right]$} & {$\left[\tau_{2}\right]$} & {$\left[\tau_{3}\right]$} & {$\left[\tau_{4}\right]$} & {$\left[\tau_{5}\right]$} \\
\hline 2 & 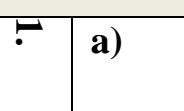 & & & & $\begin{array}{l}\text { uso } \\
\text { implícito }\end{array}$ & \\
\hline E & b) & & uso parcial & & & \\
\hline 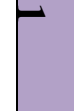 & c) & & & & & $\begin{array}{l}\text { uso } \\
\text { implícito }\end{array}$ \\
\hline & d) & & uso parcial & & & \\
\hline & $\begin{array}{l}\text { PARTE } \\
\text { II }\end{array}$ & Quanto a mo & ão e resoluç & & & \\
\hline & 2. & Houve modeli & mas apresen & uma s & dlar & \\
\hline & 3. & Houve modeli & apresentou & lução & & \\
\hline & 4. & Não resolveu & & & & \\
\hline & PARTE I & {$\left[\tau_{1}\right]$} & {$\left[\tau_{2}\right]$} & {$\left[\tau_{3}\right]$} & {$\left[\tau_{4}\right]$} & {$\left[\tau_{5}\right]$} \\
\hline f & \begin{tabular}{l|l} 
1. & a)
\end{tabular} & uso completo & & & & \\
\hline$\underline{\underline{\theta}}$ & b) & uso completo & & & & \\
\hline & c) & & & & & $\begin{array}{l}\text { uso } \\
\text { completo }\end{array}$ \\
\hline
\end{tabular}

Tangram - Revista de Educação Matemática, Dourados - MS - v.3 n.2, pp. 102-126 (2020)

Este obra está licenciada com uma Licença Creative Commons Atribuição-NãoComercial-CompartilhaIgual 3.0 Brasil. 


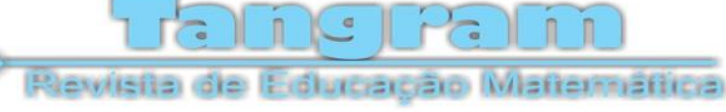

e-1SSN: 2595-0967

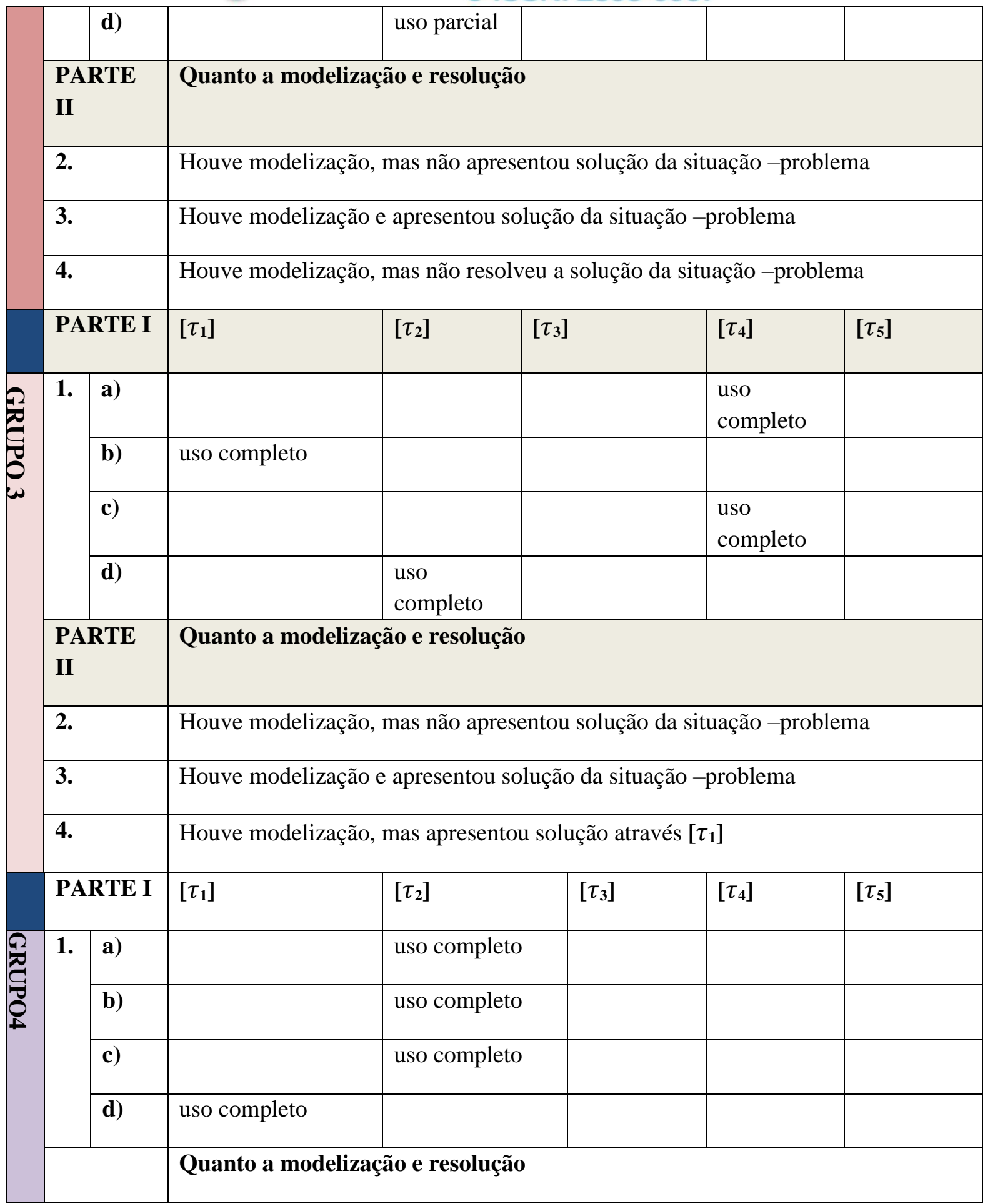

Tangram - Revista de Educação Matemática, Dourados - MS - v.3 n.2, pp. 102-126 (2020)

Este obra está licenciada com uma Licença Creative Commons Atribuição-NãoComercial-CompartilhaIgual 3.0 Brasil. 


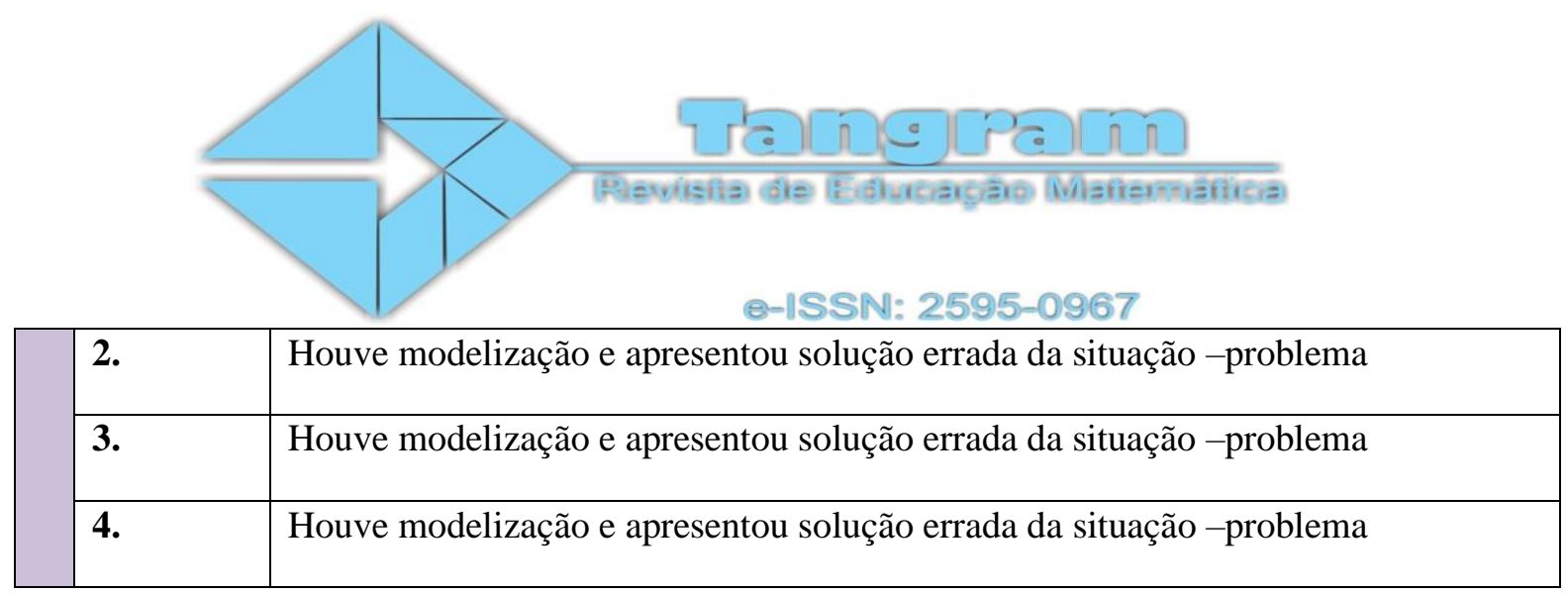

Fonte: Autores (2019)

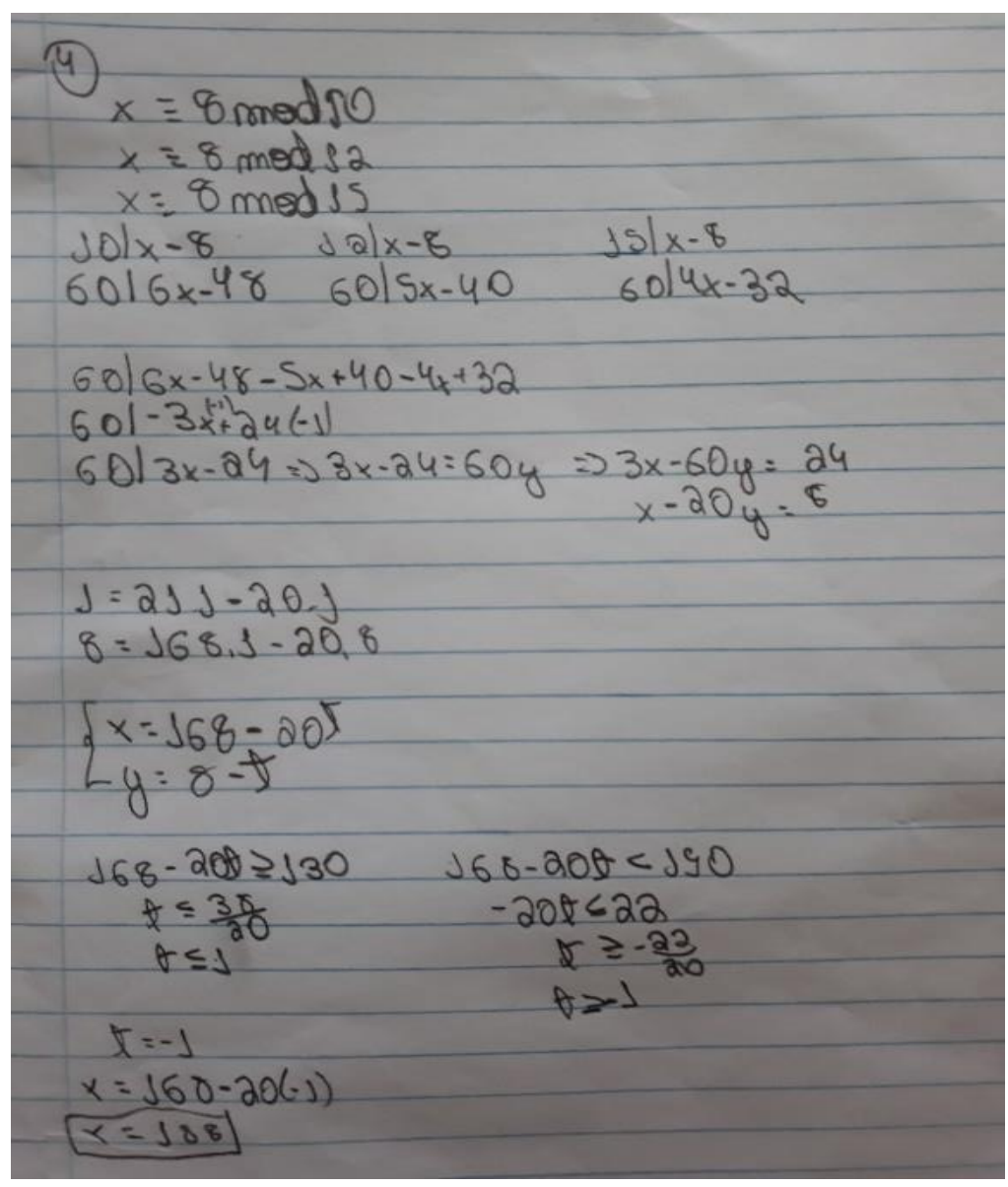

Figura 1- produção do grupo 4 Fonte: Autores (2019)

Este fato reforça parcialmente a hipótese de que algumas técnicas poderiam não ser encontradas nos registos, bem como a escolha de técnica com resolução penosa por ser aquela mais usual, ampliando a probabilidade de ocorrência de erros na sua aplicação, conforme análise a priori realizada.

Tangram - Revista de Educação Matemática, Dourados - MS - v.3 n.2, pp. 102-126 (2020)

Este obra está licenciada com uma Licença Creative Commons Atribuição-NãoComercial-CompartilhaIgual 3.0 Brasil. 


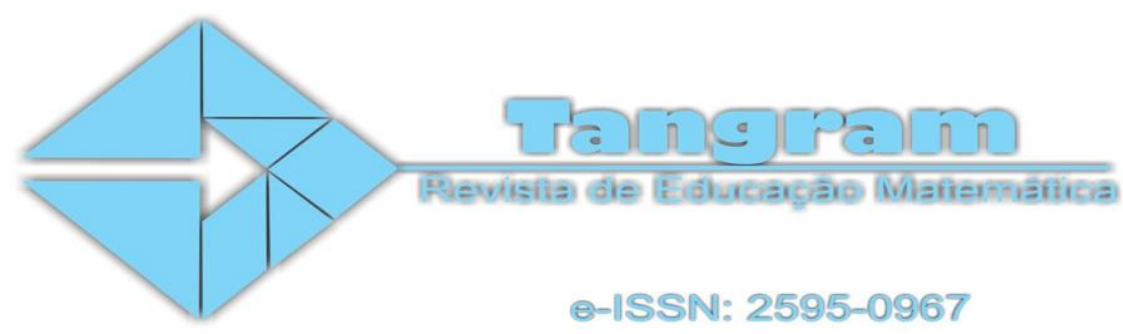

A técnica mais empregada com solução correta da questão foi a [ $\left.\tau_{2}\right]$. Isto se deve ao fato que esta é facilitada pelo uso do algoritmo de Euclides e o teorema de Bézout articulados para obtenção de uma solução particular e do teorema de Gauss que estabelece critério quanto a existência de solução. Conceitos trabalhados oficialmente na disciplina Teoria de Números mostram que a escolha da técnica está relacionada com o contrato didático (Brousseau, 1996).
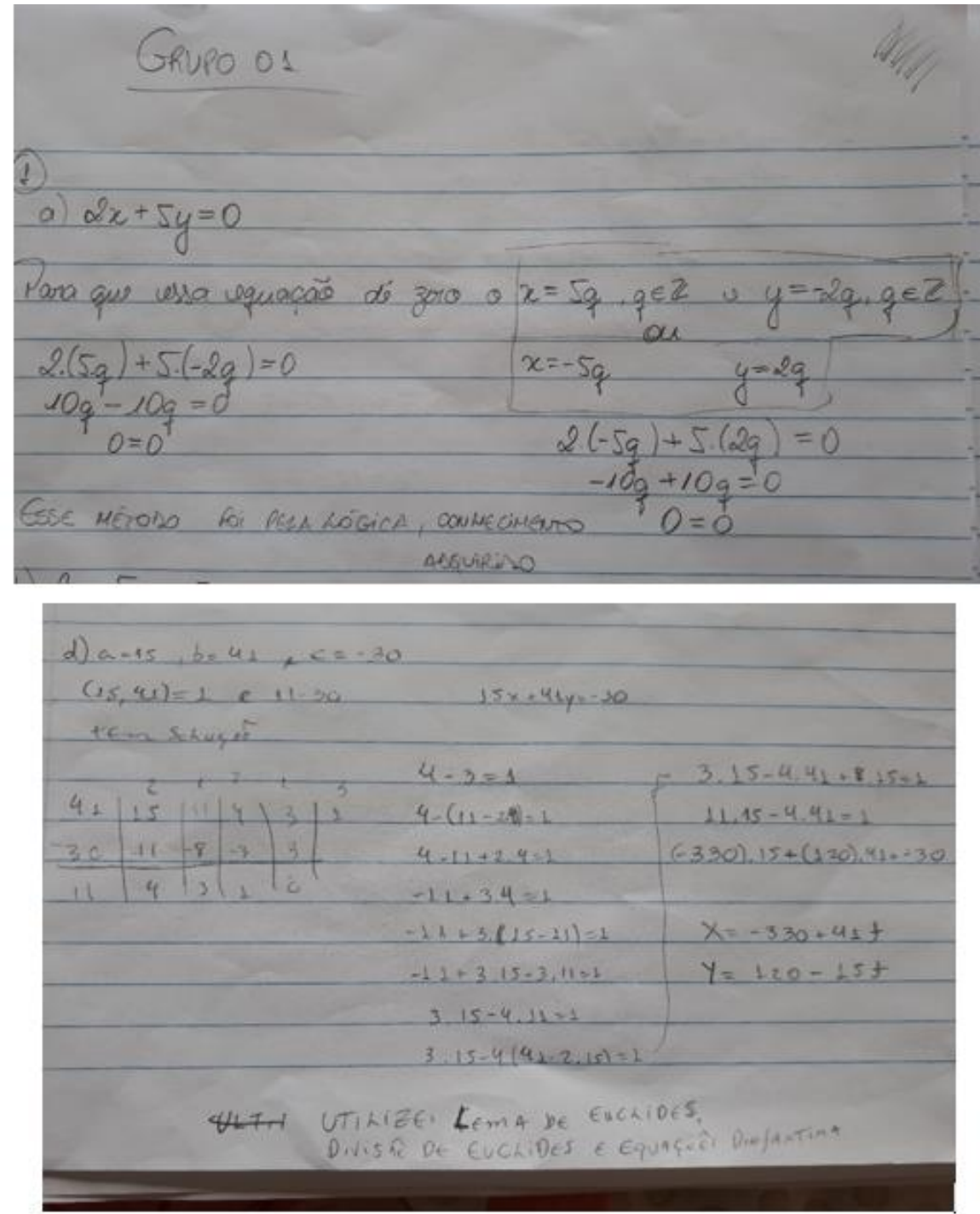

Figura 2- Produção do grupo 3 Fonte: Autores (2019)

Tangram - Revista de Educação Matemática, Dourados - MS - v.3 n.2, pp. 102-126 (2020)

Este obra está licenciada com uma Licença Creative Commons Atribuição-NãoComercial-CompartilhaIgual 3.0 Brasil. 


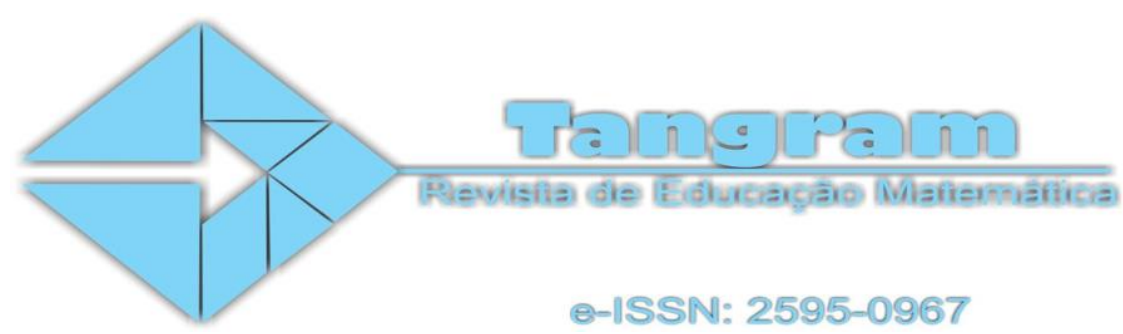

Identificamos também que as técnicas $\left[\tau_{1}\right],\left[\tau_{4}\right]$ e $\left[\tau_{5}\right]$ foram igualmente utilizadas com a obtenção correta da solução em maiorias dos registos. Exceto, para o grupo I (Figura 2) que aplicou implicitamente $\left[\tau_{4}\right]$ e justificou a sua técnica equivocadamente por lógica com base em conhecimento adquirido. Parece que esse grupo utilizou "Uma técnica pessoal" que permite resolver um único tipo de tarefas pessoais, que em nosso caso, foi inadequada para o tipo de tarefa enfrentada.

Observamos também que alguns alunos participantes encontraram dificuldades para justificar em seus grupos as atividades propostas, e não identificaram os conceitos aplicados nessa parte, pois estes não conseguiram relacionar a teoria com a prática e, como consequência, a solução do problema não foi encontrada.

Nos problemas abertos, a maioria dos grupos apresentou dificuldades em trabalhar com problemas com mais de uma solução, neste caso, percebe-se que os estudantes não associam, diante de problema contextualizados uma equação com duas incógnitas, a possibilidade de existência de várias soluções, isto confirma o que Costa (2007).

O que pode indicar que, embora afirmem trabalhar com problemas com mais de uma solução, neste caso, a maioria deles não associa uma equação com duas incógnitas à possibilidade de existência de várias soluções. Ou seja, esses problemas, apesar de algumas vezes serem trabalhados com os alunos, não fazem parte daqueles que costumam ser trabalhados frequentemente pelos professores do Ensino Médio e, quando trabalhados, não são solucionados através das ferramentas indicadas pela Teoria Elementar dos Números, reflexo talvez, do que é apontado nos livros didáticos do Ensino Médio.(Costa, 2007, p. 114)

\section{Considerações finais}

A experimentação evidenciou que existem técnicas que os alunos têm conhecimentos necessários para aplicá-las. Mas devido às práticas de classe, eles privilegiaram as técnicas tentativa e erro, Algoritmo de Euclides / Teorema de Bézout/Teorema de Gauss articulados, embora elas não se mostrassem sempre eficazes para obtenção das soluções das ED lineares de $1^{\text {o }}$ grau em $Z$. Nesse sentido, faz-se necessário uma reorganização e rearticulação dos

Tangram - Revista de Educação Matemática, Dourados - MS - v.3 n.2, pp. 102-126 (2020) 


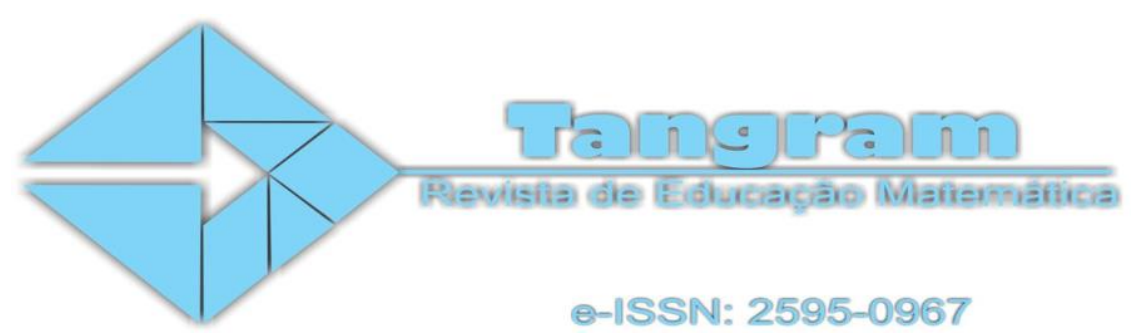

conhecimentos dos estudantes para que possam ampliar suas organizações matemáticas. É importante saber fazer, mas é preciso levar em consideração o tempo e as tecnologias que justificam as técnicas escolhidas.

Percebe-se que neste contexto os estudantes sabem mobilizar seus conhecimentos estritamente matemáticos para modelizar corretamente uma situação contextualizada. Todavia, eles apresentam dificuldades em correlacionar a solução geral da equação diofantina com a solução da situação-problema dada. Este fato permite considerar que estes estudantes apresentam no processo investigativo entraves na interpretação de problemas não matemáticos.

Este trabalho também possibilitou um olhar para as equações diofantinas na Educação básica como fonte para um aprofundamento dos estudantes em conceitos como divisibilidade, MDC e MMC com vista à resolução de problemas abertos para ampliar a capacidade de identificar oportunidades de utilização da matemática para resolver problemas, aplicando conceitos, procedimentos e resultados para obter soluções e interpretálas segundo os contextos das situações. Através desse tipo de trabalho os alunos podem ser ajudados a refletir sobre um caminho para a construção de uma transposição didática para as séries finais do ensino fundamental e médio.

\section{Referências}

Brasil. (1999) Secretaria de Educação Média e Tecnológica do Ministério da Educação. Parâmetros Curriculares Nacionais para o Ensino Médio. Ciências da Natureza, Matemática e suas tecnologias. Brasília: SEMT/ MEC.

Brasil. (2009) Matriz de Referência para o ENEM. Brasília: Ministério da Educação.

Brasil. (2017)Ministério da Educação. Base Nacional Curricular Comum: versão final. Secretaria da Educação Fundamental. Brasília, 2017. Disponível em: Acesso em: 18 de setembro.

Brousseau, G.(1996) Fundamentos e métodos da didática da matemática. In: BRUN J. Didáctica das matemáticas. Horizontes Pedagógicos: Instituto Piaget, Lisboa.

Tangram - Revista de Educação Matemática, Dourados - MS - v.3 n.2, pp. 102-126 (2020) 


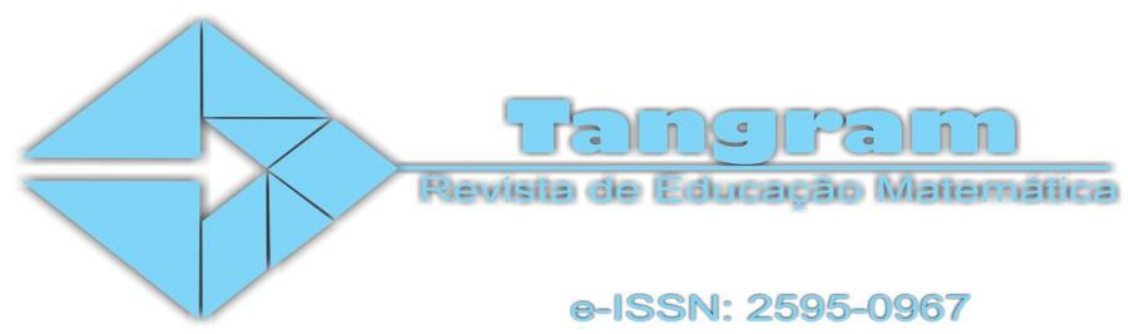

Chachoua, H., Bessot, A. (2019)La notion de variable dans le modèle praxéologique. Revista Educação Matemática e Pesquisa, São Paulo, v.21, n.4, p. 234-247.

Ore, O. (1988) Number Theory and Its History. New York, Dover Publications Inc. Cap 68,p. 116-207,.

Chevallard, Y. (1999) Analyse des pratiques enseignantes et didactique des mathématiques: L'approche anthropologique. Recherches en Didactique des Mathématiques, Vol 19, $\mathrm{n}^{\circ}$ 2, pp. 221-266. Grenoble, France: La Pensée Sauvage.

Coelho, S. P., Machado, S. D. A., Maranhão, M. C. S. A. (2003), Projeto: qual a álgebra a ser ensinada em cursos de formação de professores de matemática? In: II Seminário Internacional de Pesquisa em Educação Matemática, II SIPEM. Anais do II SIPEM, . v. 1.p. 1-19.

Costa, S. C. (2007)As equações diofantinas lineares e o Professor de matemática do ensino médio. Dissertação (Mestrado em Educação Matemática). Pontifícia Universidade Católica de São Paulo.

Courant, R.; Robbins, H. (2000) O que é Matemática? Tradução de: Adalberto da Silva Brito. Rio de Janeiro: Ciência Moderna.

Fernandes, A. M.V; Avritzer, D. (2010) Fundamentos de Álgebra. Editora UFMG.

Gascón, J. (2001)Incidencia del modelo epistemológico de las matemáticas sobre las prácticas docentes. Revista Latinoamericana de Investigación en Matemática Educativa (RELIME), 4(2), 129-159.

Gascón, J. (2011) Las tres dimensiones fundamentales de un problema didáctico: El caso del álgebra elemental. Revista Latinoamericana de investigación en Matemática Educativa, pp. 203-231.

Groenwald, C. L. Oliveira, et al. (2018)Teoria dos Números e suas Aplicações no Processo de Ensino e Aprendizagem. Disponível em < http://miltonborba.org/CD/Interdisciplinaridade/Encontro Gaucho Ed Matem/cient ificos/CC79.pdf>. Acesso em: 02 junho 2018.

Pommer, W. M.; Pommer, C. P. C. R. (2012) Equações Diofantinas Lineares: Um viés Histórico/epistemológico como recurso para introduzir diferentes estratégias de resolução de problemas. Revista de Ensino de Ciências e Matemática, v. 3, p. 28-42. Disponível em: <http://revistapos.cruzeirodosul.edu.br/index.p

Tangram - Revista de Educação Matemática, Dourados - MS - v.3 n.2, pp. 102-126 (2020) 

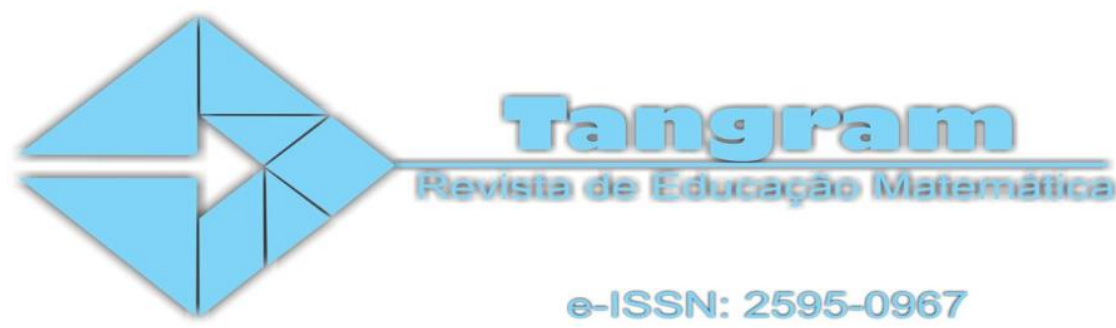

Contribuições dos Autores

$1^{\text {a }}$ autor: conceitualização; curadoria de dados; análise formal; investigação; metodologia; visualização; redação - rascunho original; redação - revisão e edição.

$2^{\mathrm{a}}$ autor: conceitualização; curadoria de dados; análise formal; investigação; metodologia; visualização; redação - rascunho original; redação - revisão e edição.

$3^{a}$ autor: conceitualização; curadoria de dados; análise formal; investigação; metodologia; visualização; redação - rascunho original; redação - revisão e edição.

Tangram - Revista de Educação Matemática, Dourados - MS - v.3 n.2, pp. 102-126 (2020) 